\title{
Dose Response of Adrenocorticotropin and Cortisol to the CCK-B Agonist Pentagastrin
}

James L. Abelson, Ph.D., and Israel Liberzon, M.D.

Cholecystokinin (CCK) is an abundant neurotransmitter in brain. Its functional significance in humans is incompletely understood, but it may modulate activity in the hypothalamic-pituitary-adrenal (HPA) axis. To explore this hypothesis, we examined the effects of varying doses $(0$ to $0.8 \mu \mathrm{g} / \mathrm{kg}$ ) of the CCK-B agonist pentagastrin on adrenocorticotropin $(A C T H)$ and cortisol release in healthy human subjects. We also examined anxiety, heart rate $(H R)$, and blood pressure $(B P)$ responses. Pentagastrin induced large (up to $520 \%$ increase over baseline), significant and very rapid, dose-dependent elevations in ACTH and cortisol levels. Significant elevations in HR and $B P$ were seen at all doses, without clear dose-response relationships. Anxious distress and symptom responses were also somewhat dose dependent; but hormonal responses were more robustly linked to pentagastrin dose than to these subjective measures. The HPA axis response to the CCK-B agonist pentagastrin may be a direct pharmacological effect. Further work is needed to determine the mechanisms and the physiological significance of CCKmediated modulation of the human neuroendocrine stress axis. [Neuropsychopharmacology 21:485-494, 1999] (C) 1999 American College of Neurospychopharmacology. Published by Elsevier Science Inc.
KEY WORDS: Cholecystokinin; Adrenocorticotropin; Cortisol; Anxiety; Panic disorder

Cholecystokinin (CCK) is a peptide neurotransmitter widely distributed in the brain and abundant in cortex (Kreiger 1983). Two CCK receptor subtypes (designated $A$ and $B$ ) have been identified. Both are found within the central nervous system (CNS), although CCK-B receptors are far more numerous and widely distributed there (Hill and Woodruff 1990; Saito et al. 1980; Woodruff and Hughes 1991). CCK or CCK receptors are found in brain areas involved with cognitive or emotional aspects of behavior, such as prefrontal cortex, cingulate, hippo-

From the University of Michigan, Department of Psychiatry, Anxiety Disorders Program, and Ann Arbor Veterans Administration Medical Center, Department of Psychiatry, Ann Arbor, Michigan.

Address correspondence to: J. L. Abelson, M.D., Ph.D., Rm. C435, Med Inn Bldg/0840, 1500 E. Medical Drive, Ann Arbor, MI 481090840 .

Received 25 February 1998; revised and accepted 22 October 1998. campus, amygdala, and the locus coeruleus (Lindefors et al. 1993; Saito et al. 1980). CCK is also colocalized or interacts with neurotransmitters thought to be involved in anxiety and affective disorders, such as serotonergic (Brodin et al. 1989; Stallone et al. 1989), GABAergic (Kaneyuki et al. 1989; Sheehan and de Belleroche 1983), and monoaminergic systems (Beresford et al. 1988; Crawley 1991; Kaneyuki et al. 1989). Considerable work, in fact, supports a role for the CCK-B receptor in anxiety states and panic attacks (Abelson and Nesse 1994; Bradwejn and Koszycki 1994; Harro et al. 1993). There is also evidence that the CCK-B receptor may play a role in modulating activity within the hypothalamic-pituitaryadrenal (HPA) axis (Abelson et al. 1994). Thus, CCK may be a modulator of emotional behavior and stress responsiveness; however, its real functional significance in humans is still poorly understood.

Significant cross-species differences exist in the function and distribution of CCK receptors (Hinks et al. 1995; Woodruff et al. 1991). Therefore, development of human probes is critical for further insight into the 
functional biology of CCK in humans. CCK-4 has been well developed as a laboratory tool for studying human panic anxiety (Bradwejn and Koszycki 1994; Bradwejn et al. 1992), but access to this probe is limited, and its neuroendocrinology has not been extensively studied. Pentagastrin is an alternative, readily available CCK-B receptor agonist. It has a higher affinity for the CCK-B receptor than CCK-4; and although it is somewhat less selective for the $\mathrm{B}$ over the A receptor, it is a highly selective agonist with minimal CCK-A receptor activity in the dose range used in human studies (Hughes et al. 1990). Its anxiogenic properties in humans are similar to those of CCK-4 (Abelson and Nesse 1994).

A number of studies have now confirmed the ability of pentagastrin, as well as other CCK-B agonists, to activate the HPA axis in humans (Abelson et al. 1994; de Montigny 1989; Degli Uberti et al. 1983; Späth-Schwalbe et al. 1988), supporting a role in stress-response modulation. Animal work also supports the idea that CCK, in addition to having anxiogenic activity, does play a significant role in hypothalamic regulation of the pituitaryadrenal axis (Mezey et al. 1986; Micevych et al. 1987; Reisine and Jensen 1986; Vanderhaeghen et al. 1985). The limited available human data suggest that the anxiogenic and stress axis activating effects of CCK-B agonism may be unrelated and are, perhaps, mediated via different pathways (Abelson et al. 1994; Le Mellédo et al. 1997). However, additional work is needed to determine definitively whether the HPA axis response to CCK-B agonists represents a direct pharmacological effect, or a nonspecific, general stress response.

To develop pentagastrin further as a probe of the CCK-B receptor in human studies and to explore the role of CCK in HPA axis modulation, we sought to determine whether CCK-B receptor agonism stimulates adrenocorticotropin (ACTH) and cortisol secretion in a dose-dependent fashion. We initially determined the threshold dose needed to produce symptom reports and then examined the dose response across a full range, from just above the detectable level, as determined by the threshold finding study, to a dose expected, on the basis of prior work (McCann et al. 1995), to produce a maximal HPA axis response. A dose-dependent release of HPA axis hormones, not mediated by anxiety or subjective distress, would support the pharmacological and physiological relevance of the CCK-B receptor to human HPA axis activation and indicate a need for further work to define the mechanisms and functional significance of CCK-B receptor/HPA axis interactions.

\section{METHODS}

\section{Subjects}

Subjects were 19 female and 16 male healthy adults, with a mean age of $26.3 \pm 7.7$ years (range, $18-45$ years), recruited through newspaper advertising and paid $\$ 100$ for completion of the study. They were screened using the Structured Clinical Interview for DSM-IV (SCID) to ensure that none had any Axis I psychiatric disorders. Subjects received an abbreviated Family Informant Schedule and Criteria (FISC) interview (Mannuzza et al. 1985) to exclude those with first degree relatives with affective or anxiety disorders. All subjects provided written informed consent. All subjects were free of serious medical illness during the prior 3 months, had no history of DSM-IV alcohol or drug dependence, had no drug or alcohol abuse in the past 6 months, had no regular alcohol use during the past 6 months greater than four cans of beer per week or the equivalent, and did not smoke more than 20 cigarettes per day. All subjects were within $-10 \%$ and $+25 \%$ of ideal body weight, had a negative urine drug screen, and had normal screening laboratory tests (blood counts, electrolytes, glucose, liver and renal functions). Female subjects were premenopausal, were not taking birth control pills, and were studied within the first 10 days after the onset of menstruation (to preclude the possibility of pregnancy and control for effects of menstrual cycle on the HPA axis).

\section{Threshold Finding Experiment}

To determine the threshold dose for subjective symptom production, we conducted an "up-and-down" sensitivity trial (Dixon and Massey 1969). In this procedure, a priori decisions are made about a starting dose (we chose $0.05 \mu \mathrm{g} / \mathrm{kg}$ ), a dose increment (also $0.05 \mu \mathrm{g}$ / $\mathrm{kg}$ ), and definition of a target response (we defined a symptom response as a 4-point rise from baseline in the postinfusion Acute Pain Inventory total score (described below) after correction for placebo injection symptom levels). The first subject is administered the starting dose. If a symptom response occurs, the next lower dose is tried in the next subject. If no symptom response occurs, then the next higher dose is used. This "up-and-down" dosing approach is repeated until six to eight subjects have been run, allowing fairly rapid and reliable determination of the threshold dose required to achieve the targeted response. We used seven subjects in this trial and examined ACTH responses to determine if any doses that were subthreshold for symptoms could produce at least a $20 \%$ increase in ACTH over basal levels.

Subjects were studied in the afternoon, with timing and procedures similar to that used in the full, doseresponse study (see below), with the exception that a placebo injection (normal saline) was administered 1 hour before the pentagastrin. To detect pharmacologically meaningful symptom thresholds, symptoms elicited by placebo were subtracted from symptoms elicited by pentagastrin for each subject. 


\section{Procedures for Dose Response Experiment}

Subjects were assigned to a placebo group or one of four dose groups $(0.2,0.4,0.6,0.8 \mu \mathrm{g} / \mathrm{kg})$ by constrained random assignment (to give approximately equal age and gender distributions in the five groups). They were admitted for study to a Clinical Research Center (CRC) at 1:00 PM. Subjects and CRC staff were blind to group assignment. An intravenous catheter was inserted into a forearm or antecubital vein and kept open with a slow, normal saline drip. This line was used for both drug injection and blood sampling. Following IV insertion, subjects rested comfortably in bed for 2 hours to accommodate to the research setting. Baseline blood samples were obtained at 3:00 and 3:28 PM. The pentagastrin (commercially available Peptavlon ${ }^{\mathrm{TM}}$, Wyeth-Ayerst Laboratories, Philadelphia, PA) was prepared by the University of Michigan Investigational Drug Pharmacy by drawing the appropriate dosages into a syringe in a saline vehicle of less than $5 \mathrm{ml}$. Labeled syringes were delivered to the CRC 1 hour before infusion and kept refrigerated until used. The pentagastrin was injected by the study physician at 3:30 $\mathrm{PM}$, via a port in the IV tubing, over $10 \mathrm{~s}$, with the normal saline drip fully opened for rapid flow. Additional blood samples were obtained at 3, 5, 10, 20, 30, 45, and $60 \mathrm{~min}$ after injection. Samples for ACTH were drawn into vacutainer tubes containing ethylenediaminetetraacetic acid (EDTA) and those for cortisol were drawn into heparinized tubes. Samples were immediately placed on ice and were spun, separated, and frozen at $-70^{\circ} \mathrm{C}$ within $30 \mathrm{~min}$.

\section{Additional Measures and Assays}

At the time of screening, subjects completed a Beck Depression Inventory (BDI) (Beck 1978), the Anxiety Sensitivity Index (ASI) (Reiss et al. 1986), and the Speilberger State/Trait Anxiety Inventory (STAI) (Spielberger et al. 1969).

Heart rate (HR), systolic blood pressure (SBP), and diastolic blood pressure (DBP) were measured using an AirShields automated monitor. Recordings were made every 10 min from -30 minutes until -10 min before injection, every 2 min from -10 until +10 min after injection, and every $10 \mathrm{~min}$ thereafter until blood sampling was completed.

Physical and emotional symptoms were recorded, at the time of each blood sample, using a previously described (Abelson and Nesse 1994) version of the Acute Panic Inventory (API) (Dillon et al. 1987) and visual analog scales. The modified API provides ratings on a 4-point scale (none, mild, moderate, severe) of subjective and somatic symptoms of panic attacks as listed in DSM-IV. Subjects also give a yes or no response to the question, "Did you, or are you now having a panic at- tack?" We calculated two dependent variables from the API, the number of symptoms present (those rated at least mild), and the total symptom intensity (sum of individual symptom ratings). To determine the presence of panic attacks, we applied the criteria for a pharmacologically induced panic attack originally proposed by Klein's group (Dillon et al. 1987), quantified by requiring that the symptom profile meet DSM-IV's 4-symptom criterion and that there be at least a 2-point increase from baseline in the subject's rating of anxiety. For the visual analog scales (VAS), subjects rate themselves on 10 different feeling states (happy, drowsy, nervous, sad, calm, depressed, anxious, energetic, fearful, and angry) by marking a line on a $100-\mathrm{mm}$ visual analog scale ranging from "not all" to "most ever." A composite measure of anxious distress was calculated by summing the VAS measurements for "anxious," "nervous," and "fearful," and subtracting the measure for "calm."

Cortisol was assayed using the direct, nonextraction, Coat-A-Count tube assay from Diagnostics Products Corporation (Los Angeles, CA). ACTH was assayed using the Allegro HS ACTH IRMA from Nicholas Institute (San Juan Capistrano, CA). Sensitivities were $6 \mathrm{pg} /$ $\mathrm{ml}$ for ACTH and $0.2 \mu \mathrm{g} / \mathrm{dl}$ for cortisol, with coefficients of variation $(\mathrm{CV})$ of less than $10 \%$.

\section{Analyses}

In the threshold finding study, we followed the method of Dixon (Dixon and Massey 1969) to estimate the mean dose needed to produce a detectable symptom response. ACTH responses were calculated for each subject as percentage change from baseline (peak postinjection ACTH minus mean of two pre-injection values, multiplied by 100).

In the dose-response study, the five dose groups were first compared on screening and baseline measures using one-way analysis of variance (ANOVA). Hormonal data were log-transformed before analysis. ACTH and cortisol were initially analyzed using a repeated-measures ANOVA, with dose groups as a between-subject variable and time (two pre-injection and five postinjection measures) as a within-subjects variable. Dose group differences in response to pentagastrin would be reflected in a group-by-time interaction in these analyses. We also calculated an integrated response measure for each subject, for ACTH and cortisol, by calculating the area under the postinjection curve (using trapezoidal approximation) and subtracting the area under the pre-injection curve (multiplied by a constant to approximate the same time duration as the postinjection curve). We added a constant to the resultant difference (to avoid negative values) before log transformation. One-way ANOVAs were used to determine whether the dose groups differed on these response measures and Fisher's PLSD post hoc tests were 
used to locate specifically the groups that differed when the group main effect was significant.

For cardiovascular measures, a mean baseline was calculated by averaging pre-injection values. Because all meaningful HR and BP fluctuations occurred in the first $10 \mathrm{~min}$ after pentagastrin, we calculated our response measure by averaging the values across this 10min period and subtracting the mean baseline. We also calculated a peak-response measure by subtracting the mean baseline from the highest value obtained in the 10-min postinjection period. The effects of pentagastrin were verified using paired $t$-tests to compare postinjection values to pre-injection values in all groups combined. Dose group differences were tested using oneway ANOVAs and Fisher's post hocs, as described above for ACTH and cortisol.

For all subjects who received pentagastrin, symptom responses occurred within a minute of injection and waned within $3 \mathrm{~min}$. Significant group differences in symptom measures appeared only in the 3-min, postinjection ratings, which reflected the maximal levels experienced in the prior few minutes. Pre-injection values were averaged to provide a baseline measure for each symptom variable (number of symptoms, symptom intensity, and subjective anxious distress, see above). Symptom response was calculated as the difference between the 3-min, postinjection rating and the mean baseline. Paired $t$-tests and one-way ANOVAs were used as described above for cardiovascular data. Relationships between variables, using the entire subject sample, were explored using Pearson product-moment correlation and multiple regression analyses.

\section{RESULTS}

\section{Threshold Finding Study}

The seven subjects were administered the following doses (+ indicates symptom response present, - indicates symptom response absent): $0.05(-), 0.1(-), 0.15$ $(+), 0.1(+), 0.05(-), 0.1(-)$, and $0.15(+) \mu \mathrm{g} / \mathrm{kg}$. The estimated mean dose needed to produce a detectable symptom response was $0.11 \mu \mathrm{g} / \mathrm{kg}$. The three subjects who had symptom responses (receiving 0.15, 0.15, and $0.1 \mu \mathrm{g} / \mathrm{kg}$ doses) had 72, 33, and 19\% ACTH rises, respectively. The four subjects who did not have symptom responses showed minimal changes in ACTH levels, with a mean decline ( $-3 \%$ change) from baseline to postinjection.

\section{Dose-Response Study}

Based on the above study we evaluated 0, 0.2, 0.4, 0.6, and $0.8 \mu \mathrm{g} / \mathrm{kg}$ doses. The five dose groups did not differ significantly in mean age, sex distribution, height, weight, or scores on any of the screening inventories
( $p>.22$ for all tests). The mean Beck Depression Inventory score was $3.1( \pm 3.4)$ and the State/Trait Anxiety scores were $5.5( \pm 0.9)$ and $7.6( \pm 1.3)$, respectively, consistent with a "normal" population with low levels of depression and anxiety. There were no significant group differences on any pre-injection (baseline) hormone, cardiovascular, or symptom measures. There were no differences between males and females on any hormonal, cardiovascular, or symptom responses to pentagastrin.

Hormone Data. Pentagastrin produced significant, dose-dependent elevations in ACTH and cortisol. Raw data graphs are presented in Figure 1. Highly significant main effects of time in the repeated measures ANOVAs $(\mathrm{F}=29.1, \mathrm{df}=6,180, p<.0001$ for ACTH and $\mathrm{F}=38.2, \mathrm{df}=6,180, p<.0001$, for cortisol) reflect the robust release of both hormones by pentagastrin. Significant group-by-time interactions $(\mathrm{F}=8.3, \mathrm{df}=24,180, p<$ .0001 and $\mathrm{F}=4.9, \mathrm{df}=24,180, p<.0001$, respectively) support the dose-dependent nature of this response.

The dose effect is highlighted in the graphs and analyses of the net, integrated response data (see Figure 2). For cortisol, the main effect of group was significant
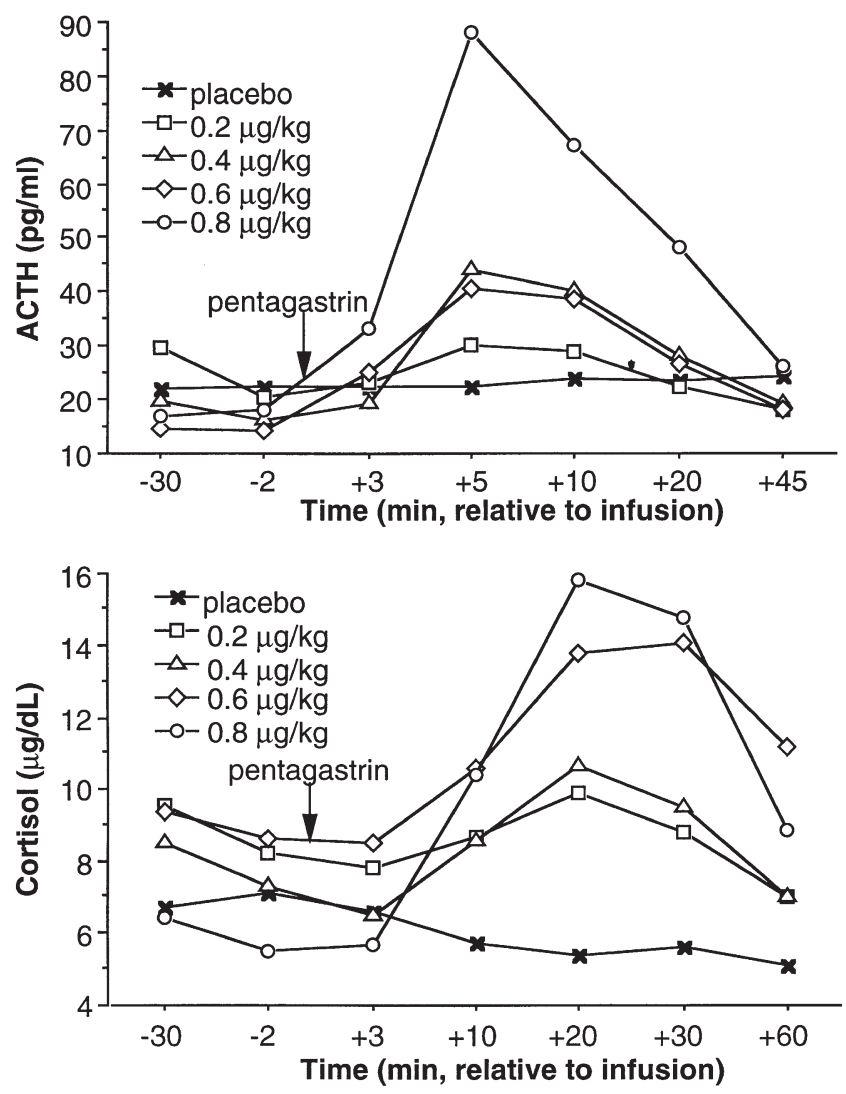

Figure 1. ACTH (top) and cortisol (bottom) responses to placebo and four different doses of pentagastrin; values are group means ( $n=7$ in each group). 
$(\mathrm{F}=10.6, \mathrm{df}=4,30, p<.0001)$ and Fisher's PLSD post hoc tests showed that all four dose groups had significantly greater cortisol responses than the placebo group, that the higher dose groups $(0.6$ and $0.8 \mu \mathrm{g} / \mathrm{kg}$ ) had significantly greater responses than the lowest dose group $(0.2 \mu \mathrm{g} / \mathrm{kg})$, and the $0.8 \mu \mathrm{g} / \mathrm{kg}$ group had a significantly greater response than the $0.4 \mu \mathrm{g} / \mathrm{kg}$ group $(p<.04$ for all comparisons). For ACTH, the main effect of group was significant $(\mathrm{F}=6.7, \mathrm{df}=4,30, p=.0006)$, and Fisher's PLSD post hoc tests showed that all of the dose groups except the lowest had significantly greater ACTH responses than the placebo group, and that the highest dose group $(0.8 \mu \mathrm{g} / \mathrm{kg})$ had significantly greater responses than the three lower $(0.2,0.4$, and 0.6 $\mu \mathrm{g} / \mathrm{kg}$ ) dose groups ( $p<.04$ for all comparisons).

Mean increases over baseline (postinjection peak minus mean baseline $\times 100 \%$ ) in the five groups (listed in order of increasing dose) were 135, 163, 275, 353, and $521 \%$ for ACTH and 109, 141, 168, 170, and 314\% for cortisol. There were no differences among the four pentagastrin groups in time from injection to hormone
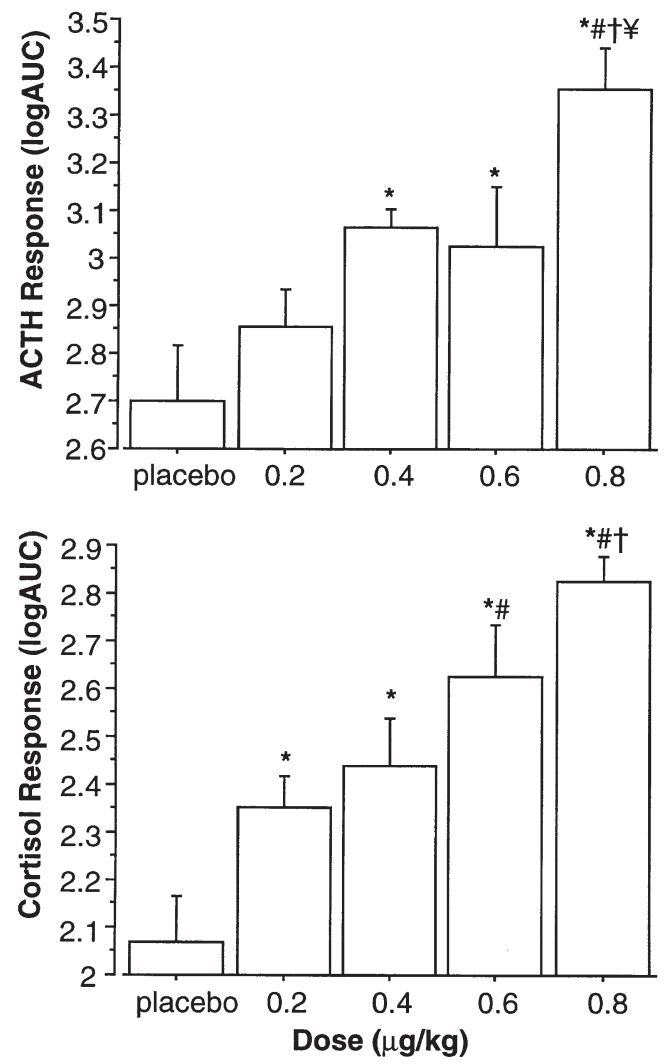

Figure 2. Net, integrated ACTH (top) and cortisol (bottom) responses (see text for derivation) to placebo and four different doses of pentagastrin; values are means \pm SEM $(n=7$ in each group); *significantly different from placebo $(p<.04)$; \# significantly different from 0.2 dose group $(p<.04)$; ${ }^{\dagger}$ significantly different from 0.4 dose group $(p<.04)$; $¥$ significantly different from 0.6 dose group $(p<.02)$. peak. The mean time to peak for all subjects receiving pentagastrin was $6.6 \pm 3.3 \mathrm{~min}$ for ACTH and $24.0 \pm$ $9.3 \mathrm{~min}$ for cortisol.

Cardiovascular Data. Pentagastrin produced significant rises in HR and BP. Paired $t$-tests for all groups combined showed significantly higher HR, SBP, and DBP during the $10 \mathrm{~min}$ after injection than during the pre-injection baseline $(t>5.3, \mathrm{df}=34, p<.001$ for all three variables). As can be seen in Figure 3, there was no HR response to placebo, but HR rose similarly in all four pentagastrin dose groups. The group effect was significant in the ANOVA ( $\mathrm{F}=3.3, \mathrm{df}=4,30, p=.02)$, and post hoc tests confirmed that each of the dose groups differed significantly in HR response from the placebo group ( $p<.04$ for each), but none of the pentagastrin groups differed from each other $(p>.28)$. SBP and DBP behaved similarly to HR (Figure 3), although the ANOVA group effects were not significant for ei-

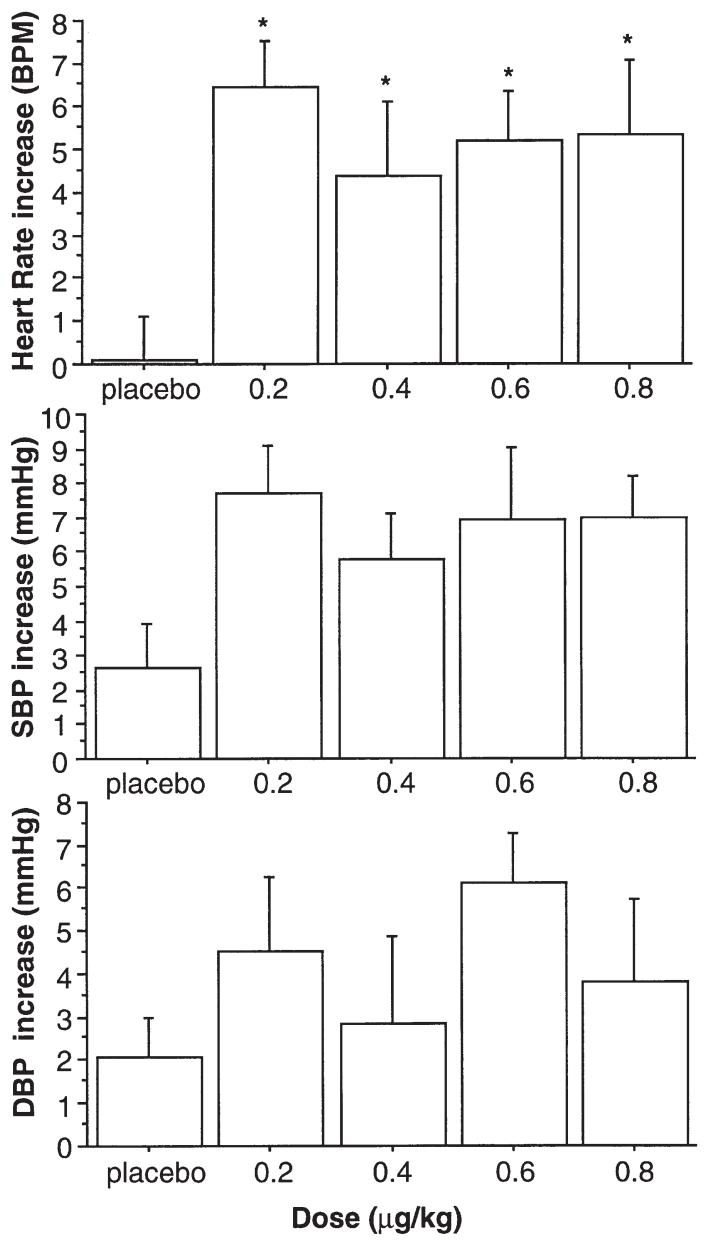

Figure 3. Heart rate and blood pressure responses to placebo and four different doses of pentagastrin; values are means $\pm \operatorname{SEM}(n=7$ in each group); * significantly different from placebo $(p<.04)$. 
ther of these variables $(\mathrm{F}=1.7, \mathrm{df}=4,30, p=.16$, and $\mathrm{F}=$ $.9, \mathrm{df}=4,30, p=.46$, respectively). Identical results were obtained using peak response measures (maximum postinjection level minus mean baseline) for all three cardiovascular variables (data not shown).

Symptom Data. Pentagastrin produced significant increases in symptom reports. Paired $t$-tests for all groups combined showed significantly higher numbers of subjectively reported panic attack symptoms, greater symptom intensity, and elevated anxious distress $3 \mathrm{~min}$ after injection than at pre-injection baselines $(t>6.9, \mathrm{df}=$ $34, p<.0001$ for all three variables). The ANOVA group effects were significant for all three symptom variables $(\mathrm{F}=4.3, \mathrm{df}=4,30, p=.007 ; \mathrm{F}=12.2, \mathrm{df}=4,30, p<.0001 ;$ and $\mathrm{F}=8.1, \mathrm{df}=4,30, p=.0002$, respectively). The ANOVA and post hoc tests (see Figure 4) show that there were moderate symptom responses to the $0.2 \mu \mathrm{g} /$
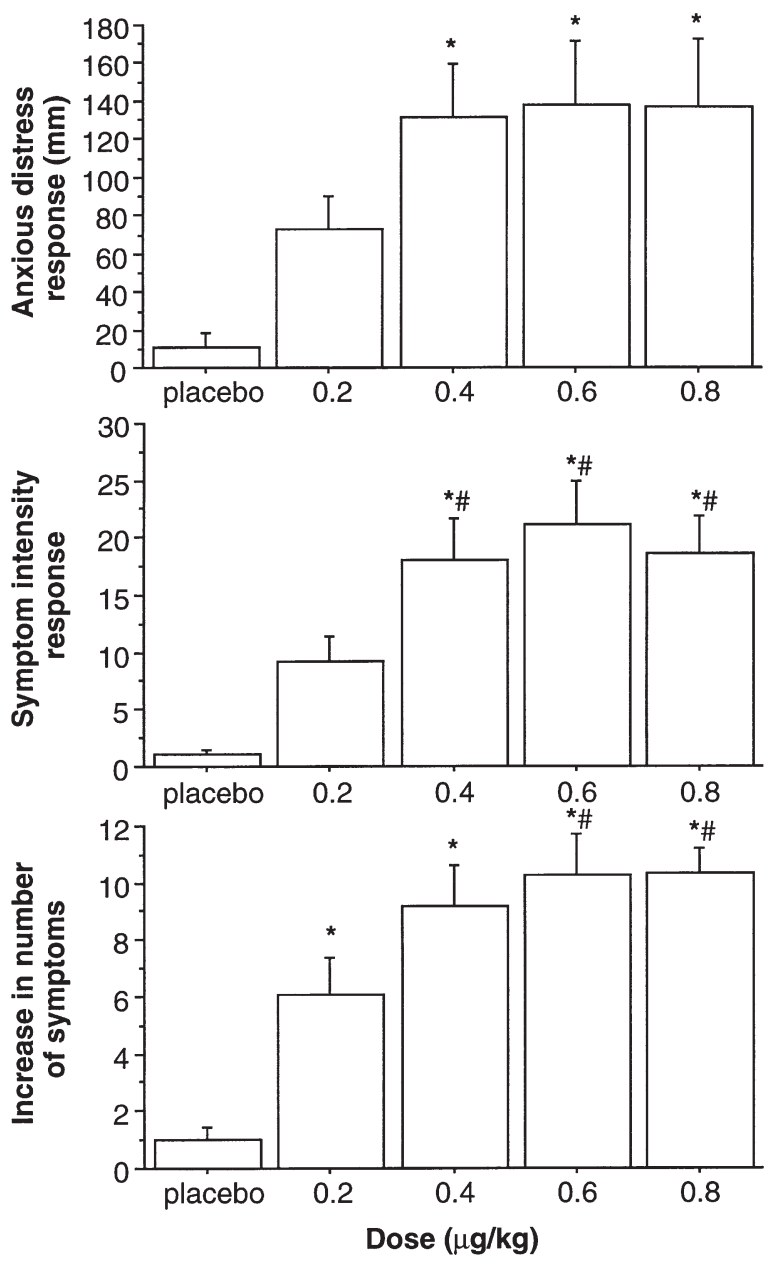

Figure 4. Panic symptom and anxious distress responses (see text for derivation) to placebo and four different doses of pentagastrin; values are means \pm SEM $(n=7$ in each group); *significantly different from placebo $(p<.004)$; \#significantly different from 0.2 dose group $(p<.05)$. $\mathrm{kg}$ dose, but large responses in the three higher dose groups, all of which differed significantly from the placebo group. The three higher dose groups did not differ significantly from each other in symptom responses.

No subjects in the placebo group experienced a panic attack. Two subjects (28\%) in each of the $0.2,0.4$, and 0.8 $\mu \mathrm{g} / \mathrm{kg}$ dose groups experienced panic attacks. Three subjects $(43 \%)$ in the $0.6 \mu \mathrm{g} / \mathrm{kg}$ dose group experienced a panic attack. There was no dose group effect on the rate of panic (Chi Square $=3.6, \mathrm{df}=4, p=.46$ ).

Correlations. There were no significant relationships between hormone responses to pentagastrin and responses on any cardiovascular measure. Responses on the three cardiovascular measures (HR, SBP, DBP) were all highly correlated with each other $(\mathrm{r}=.5$ to $.7, p<$ $.001, n=34)$. The ACTH and cortisol responses were strongly correlated $(\mathrm{r}=.63, p<.0001, n=34)$. Screening measures of depression and anxiety (BDI, ASI, STAI) did not significantly predict ACTH, cortisol, or cardiovascular responses to pentagastrin.

Simple correlations showed significant relationships between endocrine and symptom responses to pentagastrin, but both were also related to dose, so the relationships between these variables were examined in multiple regression analyses that allowed the dose effect to be partialled out. Dose, anxious distress, and symptom intensity together accounted for $53 \%$ of the variance in cortisol response, but in this multiple regression analysis (multiple $\mathrm{r}=.73, p<.0001 ; n=35$ ), only dose was a significant, independent predictor of cortisol response $(p<.0001$ for dose, $p=.56$ for anxious distress, and $p=.83$ for panic symptom intensity). Nearly identical results were found for ACTH. Dose, anxious distress, and symptom intensity together accounted for $42 \%$ of the variance in ACTH response; but in the multiple regression (multiple $\mathrm{r}=.65, p<.0001$, $n=34$ ) only dose was an independent, significant predictor of ACTH response ( $p=.006$ for dose, $p=.85$ for anxious distress, and $p=.52$ for panic symptom intensity). There were no significant correlations between dose or symptoms and $\mathrm{BP}$ or $\mathrm{HR}$ responses to pentagastrin.

We also examined ACTH and cortisol responses to pentagastrin as a function of baseline cortisol levels [pre-injection cortisol area under the curve (AUC)]. In these analyses, we examined both integrated responses (AUC difference, as above) and peak responses (postinjection maximum minus pre-injection mean). Because we were exploring the ability of elevated baseline cortisol to inhibit activation of the HPA axis (Hermus et al. 1984), we included only the three higher dose groups because these groups had the clearest activation, with both ACTH and cortisol responses to pentagastrin, which were significantly different from placebo. We could find no significant relationship between baseline cortisol and any of the measures of ACTH or cortisol re- 
sponse to activation, either in the three groups combined ( $\mathrm{r}<.2, p>.47, n=21)$, or in each dose group examined separately (correlations negligible or positive in each group).

\section{DISCUSSION}

We have demonstrated that the CCK-B receptor agonist pentagastrin produces rapid and robust activation of the HPA axis in humans, replicating prior work (Abelson et al. 1994; Degli Uberti et al. 1983; McCann et al. 1997). Earlier work has also demonstrated ACTH and cortisol release in response to other CCK-B receptor agonists (de Montigny 1989; Koszycki et al. 1996; SpäthSchwalbe et al. 1988), supporting CCK-B receptor modulation of the HPA axis in humans. The current data extend prior work by demonstrating that a CCK-B agonist stimulates release of ACTH and cortisol in a dosedependent fashion. Pentagastrin infusion also reliably elevated heart rate and blood pressure in our subjects. We did not detect a clear dose effect in cardiovascular responses, but continuous monitoring of these variables may be necessary to detect any such dose effect, because maximal cardiovascular responses appear and disappear rapidly (Le Mellédo, personal communication) (Bradwejn et al. 1992). The data also confirm that CCK-B receptor agonism produces anxiety and paniclike symptoms, and even some panic attacks, in healthy human subjects (de Montigny 1989). The induction of panic attack symptoms and anxious distress is somewhat dose dependent, as has been previously reported in patients with panic disorder (Bradwejn et al. 1992). Our data suggest that the dose threshold for symptom provocation is the same as the threshold for HPA axis activation. However, we could detect no additional relationship between symptoms and ACTH/cortisol responses that were independent of dose effects.

One prior examination of pentagastrin dose effects on ACTH and cortisol release has been published (McCann et al. 1995). This study differed from ours in that pentagastrin was administered in the context of a social interaction challenge, but it also revealed little or no response to a $0.2 \mu \mathrm{g} / \mathrm{kg}$ dose, while equal, robust responses were seen to 0.6 and $1.0 \mu \mathrm{g} / \mathrm{kg}$ doses. The similarity in the size of the response to these two doses in the McCann et al. study suggested to us that $0.6 \mu \mathrm{g} / \mathrm{kg}$ might be a sufficient dose to produce a maximal HPA response. However, the large ACTH response in our data to a $0.8 \mu \mathrm{g} / \mathrm{kg}$ dose (520 \% increase over baseline) indicates that further work is needed to define the maximal HPA response to CCK stimulation and the minimal dose capable of eliciting it. For receptor sensitivity studies, the $0.4 \mu \mathrm{g} / \mathrm{kg}$ dose may be useful, because it produces a clear HPA axis response that is detectable in a small sample study, but does not maximally stimulate the system and, thus, may be able to detect either increased or decreased sensitivity of CCK-B receptors.

Pentagastrin's ability to activate the HPA axis in a dose-dependent fashion suggests that the CCK-B receptor may play a pharmacological role in modulating release of ACTH and cortisol. Further work is needed to determine whether this is a direct effect or mediated by other mechanisms. Our data cannot rule out the possibility that symptom responses or anxious distress may play some role in mediating or modulating the HPA axis response to pentagastrin, but the correlational analyses clearly did not support strong behavioral mediation of the dose effect on hormonal responses. Separate mediation of behavioral and hormonal responses is supported by work using CCK-4, which has shown that both cardiovascular and symptom responses to CCK-B stimulation can be reduced with propranolol (Le Mellédo et al. 1998); whereas, an HPA axis response (arginine vasopressin or AVP) was not effected by the $\beta$-blocker (Le Mellédo et al. 1997). Follow-up studies with propranolol and pentagastrin are needed. Blockade of symptom responses without reduction in HPA axis responses would provide a more definitive test of the hypothesis that the hormonal response is a direct pharmacological effect and does not reflect a general stress response to sensations and symptoms produced by the drug.

Further work is also needed to determine whether CCK is a physiologically relevant modulator of the stress axis in humans, but animal work supports the presence of substantial interaction between the HPA axis and CCK systems. CCK is localized in components of the HPA axis and is co-localized with other HPA axis hormones (Kiss et al. 1984; Larsson and Rehfeld 1981; Mezey et al. 1986; Millington et al. 1992; Rehfeld 1978; Rehfeld and Larsson 1981; Rehfeld et al. 1987; Vanderhaeghen et al. 1985). The HPA axis is directly sensitive to CCK activation (Kamilaris et al. 1992; Matsumura et al. 1983; Mezey et al. 1986; Reisine and Jensen 1986). Central CCK systems are sensitive to levels of stress and circulating glucocorticoids (Mezey et al. 1986; Siegel et al. 1987) and peripheral CCK can regulate activity in central components of the HPA axis (Chen et al. 1993).

Although these animal data strongly support physiologically meaningful interactions between CCK and the HPA axis, the specific mediating mechanisms remain unclear. There is evidence to support HPA activation by CCK via peripheral pathways (Kamilaris et al. 1992), but direct effects via central or pituitary CCK receptors have also been implicated (Kamilaris et al. 1992; Millington et al. 1992; Reisine and Jensen 1986). Both the CCK-A receptor (Luckman et al. 1993; Millington et al. 1992) and a novel (non-A, non-B) receptor subtype may be involved (Parrott and Forsling 1992; Reisine and Jensen 1986), although the human work has shown highly selective CCK-B agonists to be potent ACTH 
secretagogues (Abelson et al. 1994; de Montigny 1989; Koszycki et al. 1996). Both corticotropin-releasing hormone (CRH) (Biró et al. 1993; Kamilaris et al. 1992) and AVP (Bondy et al. 1989; DeBold et al. 1984; Mezey et al. 1986; Verbalis et al. 1987) have also been implicated as mediators in animal work. It would seem from this literature that there are important connections between CCK systems and the HPA axis and that multiple mechanisms and pathways may well be involved in their interactions. Multiple functions may be served by this complexity and both the pathways and functional significance of these interactions are likely to vary across species (Hinks et al. 1995; Woodruff et al. 1991). Clarification of mechanistic pathways and functional significance in humans will require human studies.

The present data can shed only limited light on mediating mechanisms, but pentagastrin elicited much more rapid ACTH responses than are reported with human CRH infusions [7 $\mathrm{min}$ to peak vs. about $30 \mathrm{~min}$ (Schürmeyer et al. 1984)], which argues against a CRHmediated mechanism in our subjects and may support a direct anterior pituitary effect. Pentagastrin effects are also differentiated from $\mathrm{CRH}$-induced ACTH release in that responses to CRH are inversely related to basal levels of cortisol (De Cherney et al. 1985; Hermus et al. 1984) because of negative feedback inhibition; but we could not detect evidence of similar negative feedback regulation of pentagastrin-induced ACTH release. We are examining further the relationship between ACTH response to pentagastrin and basal cortisol levels in a follow-up study by examining the response across the diurnal cycle.

The possible contribution of AVP to CCK-B induced ACTH response in humans also merits further study. CCK-8, which stimulates both CCK-A and CCK-B receptors, produces a dose-dependent release of AVP in humans, with a very rapid peak (at 2 min after injection) and a threshold dose similar to that seen in the present study with pentagastrin (Miaskiewicz et al. 1989). Although the vasopressin response to CCK may be mediated by the CCK-A receptor in some species (Parrott and Forsling 1992), it seems likely to be a CCK-B receptor effect in humans, because the selective CCK-B receptor agonist, CCK-4, produces a robust and very rapid AVP release in humans (Le Mellédo et al. 1997) which is quite similar to that seen with the non-selective agonist. Follow-up efforts to examine AVP levels in samples from this dose-response study and to correlate them with the ACTH responses are underway.

In conclusion, the clear dose-dependence of the HPA axis response to pentagastrin demonstrated in this study supports our hypothesis that this response is a pharmacological effect. The data are also consistent with our hypothesis that ACTH/cortisol release and symptom production are independent in this model. The CCK-B receptor may play a physiological role in modulating activity in the neuroendocrine stress axis. Pentagastrin is a useful probe for studying CCK-B receptor function in humans and its relevance to HPA axis activity.

\section{REFERENCES}

Abelson JL, Nesse RM (1994): Pentagastrin infusions in patients with panic disorder I. Symptoms and cardiovascular responses. Biol Psychiat 36:73-83

Abelson JL, Nesse RM, Vinik AI (1994): Pentagastrin infusions in patients with panic disorder II. Neuroendocrinology. Biol Psychiat 36:84-96

Beck AT (1978): Beck Depression Inventory (BDI). Philadelphia, Center for Cognitive Therapy

Beresford IJM, Hall MD, Clark CR, Hill RG, Hughes J (1988): Cholecystokinin modulation of $[3 \mathrm{H}]$ noradrenaline release from superfused hypothalamic slices. Neurosci Lett 88:227-232

Biró E, Sarnyai Z, Penke B, Szabó G, Telegdy G (1993): Role of endogenous corticotropin-releasing factor in mediation of neuroendocrine and behavioral responses to cholecystokinin octapeptide sulfate ester in rats. Neuroendocrinology 57:340-345

Bondy CA, Jensen RT, Brady LS, Gainer H (1989): Cholecytokinin evokes secretion of oxytocin and vasopressin from the rat neural lobe independent of external calcium. Proc Natl Acad Sci USA 86:5198-5201

Bradwejn J, Koszycki D (1994): The cholecystokinin hypothesis of anxiety and panic disorder. Ann NY Acad Sci 713:273-282

Bradwejn J, Koszycki D, Annable L, Couétoux du Tertre A, Reines S, Karkanias C (1992): A dose-ranging study of the behavioral and cardiovascular effects of CCK-tetrapeptide in panic disorder. Biol Psychiat 32:903-912

Brodin K, Rosen A, Iwarsson K, Ogren SO, Brodin E (1989): Increased levels of substance $\mathrm{P}$ and cholecystokinin in rat cerebral cortex following repeated electroconvulsive shock and subchronic treatment with a serotonin reuptake inhibitor. Acta Physiol Scand 136:613-614

Chen DY, Deutsch JA, Gonzalez MF, Gu Y (1993): The induction and suppression of c-fos expression in the rat brain by cholecystokinin and its antagonist L364,718. Neurosci Lett 149:91-94

Crawley JN (1991): Cholecystokinin-dopamine interactions. Trends Pharmacol Sci 12:232-236

de Montigny C (1989): Cholecystokinin tetrapeptide induces panic-like attacks in healthy volunteers. Arch Gen Psychiat 46:511-517

De Bold CR, Sheldon WR, DeCherney GS, Jackson RV, Alexander AN, Vale W, Rivier J, Orth DN (1984): Arginine vasopressin potentiates adrenocorticotropin release induced by ovine corticotropin-releasing factor. J Clin Invest 73:533-538

De Cherney GS, DeBold CR, Jackson RV, Sheldon WR, Island DP, Orth DN (1985): Diurnal variation in the response of plasma adrenocorticotropin and cortisol to intravenous ovine corticotropin-releasing hormone. J Clin Endocrinol Metab 61:273-279 
Degli Uberti EC, Trasforini G, Margutti AR, Rotola CA, Pansini R (1983): Effect of pentagastrin on adrenocorticotropin hormone and thyroid-stimulating hormone release in normal subjects. Horm Res 17:74-77

Dillon DJ, Gorman JM, Liebowitz MR, Fyer AJ, Klein DF (1987): Measurement of lactate-induced panic and anxiety. Psychiat Res 20:97-105

Dixon WJ, Massey FJ (1969): Introduction to Statistical Analysis (3rd ed). New York, McGraw-Hill

Harro J, Vasar E, Bradwejn J (1993): CCK in animal and human research on anxiety. Trends Pharmacol Sci 14: 244-249

Hermus ARMM, Pieters GFFM, Smals AGH, Benraad TJ, Kloppenborg PWC (1984): Plasma adrenocorticotropin, cortisol, and aldosterone responses to corticotropinreleasing factor: Modulating effects of basal cortisol levels. J Clin Endocrinol Metab 58:187-191

Hill DR, Woodruff GN (1990): Differentiation of central cholecystokinin receptor binding sites using the nonpeptide antagonists MK-329 and L365,260. Brain Res 526:276-283

Hinks GL, Poat JA, Hughes J (1995): Changes in hypothalamic cholecystokinin $\mathrm{A}_{\mathrm{A}}$ and cholecystokinin B $_{\mathrm{B}}$ receptor subtypes and associated neuropeptide expression in response to salt-stress in the rat and mouse. Neuroscience 68:765-781

Hughes J, Boden P, Costall B, Domeney A, Kelly E, Horwell DC, Hunter JC, Pinnock RD, Woodruff GN (1990): Development of a class of selective cholecystokinin type $B$ receptor antagonists having potent anxiolytic activity. Proc Natl Acad Sci USA 87:6728-6732

Kamilaris TC, Johnson EO, Calogero AE, Kalogeras KT, Bernardini R, Chrousos GP, Gold PW (1992): Cholecystokinin-octapeptide stimulates hypothalamic-pituitaryadrenal function in rats: Role of corticotropin-releasing hormone. Endocrinology 130:1764-1774

Kaneyuki T, Morimasa T, Shohmori T (1989): Action of peripherally administered cholecystokinin on monoaminergic and GABAergic neurons in the rat brain. Acta Med Okayama 43:153-159

Kiss JZ, Willians TH, Palkovits M (1984): Distribution and projections of cholecystokinin immunoreactive neurons in the hypothalamic paraventricular nucleus of the rat. J Comp Neurol 227:173-181

Koszycki D, Zacharko RM, Le Melledo JM, Young SN, Bradwejn J (1996): Effect of acute tryptophan depletion on behavioral, cardiovascular, and hormonal sensitivity to cholecystokinin-tetrapeptide challenge in healthy volunteers. Biol Psychiat 40:648-655

Kreiger DT (1983): Brain peptides: What, where, and why? Science 222:975-985

Larsson LI, Rehfeld JF (1981): Pituitary gastrins occur in corticotrophs and melanotrophs. Science 213:768-770

Le Mellédo JM, Bradwejn J, Koszychi D, Bichet DG, Bellavance $F$ (1998): The role of the $\beta$-noradrenergic system in cholecystokinin-tetrapeptide-induced panic symptoms. Biol Psychiat 44:364-366

Le Mellédo JM, Bradwejn J, Koszycki D, Boulanger JP, Cadieux A, Bellavance G, Bichet DG (1997): The role of the $\beta$-adrenergic system in behavioral and neuroendo- crine response to CCK-4. Paper presented at NCDEU Annual Meeting, Florida, May, 1997

Lindefors N, Lindén A, Brené S, Sedvall G, Persson H (1993): CCK peptides and mRNA in the human brain. Prog Neurobiol 40:671-690

Luckman SM, Hamamura M, Antonijevic I, Dye S, Leng G (1993): Involvement of cholecystokinin receptor types in pathways controlling oxytocin secretion. Br J Pharmacol 110:378-384

Mannuzza S, Fyer AJ, Endicott J, Klein DF (1985): Family Informant Schedule and Criteria. Anxiety Disorders Clinic, New York State Psychiatric Institute, 722 West 118th Street, New York, NY 10032

Matsumura M, Yamanoi A, Yamamoto S, Saito S (1983): In vivo and in vitro effects of cholecystokinin octapeptide on the release of $\beta$-endorphin-like immunoreactivity. Neuroendocrinology 36:443-448

McCann UD, Slate SO, Geraci M, Roscow-Terrill D, Uhde TW (1997): A comparison of the effect of intravenous pentagastrin on patients with social phobia, panic disorder, and healthy controls. Neuropsychopharmacology 16:229-237

McCann UD, Slate SO, Geraci M, Uhde TW (1995): Peptides and anxiety: A dose-response evaluation of pentagastrin in health volunteers. Anxiety 1:258-267

Mezey E, Reisine TD, Skirboll L, Beinfeld M, Kiss JZ (1986): Role of cholecystokinin in corticotropin release: Coexistence with vasopressin and corticotropin-releasing factor in cells of the rat hypothalamic paraventricular nucleus. Proc Natl Acad Sci USA 83:3510-3512

Miaskiewicz SL, Stricker EM, Verbalis JG (1989): Neurohypophyseal secretion in response to cholecystokinin but not meal-induced gastric distention in humans. J Clin Endocrinol Metab 68:837-843

Micevych PE, Park SS, Akesson TR, Elde R (1987): Distribution of cholecystokinin-immunoreactive cell bodies in male and female rat I. Hypothalamus. J Comp Neurol 255:124-136

Millington WR, Mueller GP, Lavigne GJ (1992): Cholecystokinin type $A$ and type $B$ receptor antagonists produce opposing effects on cholecystokinin-stimulated $\beta$-endorphin secretion from the rat pituitary. J Pharmacol Exp Ther 261:454-461

Parrott RF, Forsling ML (1992): CCK-A receptors mediate the effect of cholecystokinin on vasopressin but not on cortisol in pigs. Am J Physiol 262:R1154-R1157

Rehfeld JF (1978): Localization of gastrins to neuro- and adenohypophysis. Nature (London) 271:771-773

Rehfeld JF, Larsson LI (1981): Pituitary gastrins: Different processing in corticotrophs and melanotrophs. J Biol Chem 256:10426-10429

Rehfeld JF, Lindholm J, Andersen BN, Bardram L, Cantor P, Fenger M. Lüdecke DK (1987): Pituitary tumors containing cholecystokinin. N Engl J Med 316:1244-1247

Reisine T, Jensen R (1986): Cholecystokinin-8 stimulates adrenocorticotropin release from anterior pituitary cells. J Pharmacol Exp Ther 236:621-626

Reiss S, Peterson RA, Gursky DM, McNally RJ (1986): Anxiety sensitivity, anxiety frequency, and the prediction of fearfulness. Beh Res \& Ther 24:1-8 
Saito A, Sankaran H, Goldfine ID, Williams JA (1980): Cholecystokinin receptors in brain: Characterization and distribution. Science 208:1155-1156

Schürmeyer TH, Avgerinos PC, Gold PW, et al. (1984): Human corticotropin-releasing factor in man: Pharmacokinetic properties and dose-response of plasma adrenocorticotropin and cortisol secretion. J Clin Endocrinol Metab 59:1103-1108

Sheehan MJ, de Belleroche J (1983): Facilitation of GABA release by cholecystokinin and caerulein in rat cerebral cortex. Neuropeptides 3:429-434

Siegel RA, Düker EM, Pahnke U, Wuttke W (1987): Stressinduced changes in cholecystokinin and substance $\mathrm{P}$ concentrations in discrete regions of the rat hypothalamus. Neuroendocrinology 46:75-81

Späth-Schwalbe E, Piroth L, Pietrowsky R, Born J, Lorenz Fehm H (1988): Stimulation of the pituitary adrenocortical system in man by cerulein, a cholecystokinin-8-like peptide. Clin Physiol Biochem 6:316-320
Spielberger CD, Gorsuch RL, Lushene RE (1969): STAI Manual for the State-Trait Anxiety Inventory. Palo Alto, CA, Consulting Psychologists Press

Stallone D, Nicolaidis S, Gibbs J (1989): Cholecystokinininduced anorexia depends on seritoninergic function. Am J Physiol 256:R1138-R1141

Vanderhaeghen JJ, Goldman S, Lotstra F, et al. (1985): Coexistence of cholecystokinin- or gastrin-like peptides with other peptides in the hypophysis and hypothalamus. Ann NY Acad Sci 448:334-344

Verbalis JG, Richardson DW, Stricker EM (1987): Vasopressin release in response to nausea-producing agents and cholecystokinin in monkeys. Am J Physiol 252:R749-753

Woodruff GN, Hill DR, Boden P, Pinnock R, Singh L, Hughes J (1991): Functional role of brain CCK receptors. Neuropeptides 19:45-56

Woodruff GN, Hughes J (1991): Cholecystokinin antagonists. Ann Rev Pharmacol Toxicol 31:469-501 